\title{
Budget Deficit causes Inflation? Application to Portugal
}

Agostinho Silvestre Rosa*

\begin{abstract}
The analysis of Portuguese inflation, based on annual data from 1961 to 2012, using the Johansen Method, allows us to conclude that variation in Portuguese inflation is determined essentially by foreign inflation and by variation in the effective exchange rate, but the lagged variation of budget deficit seems to causes variation of inflation in the studied period. In the long run there are two long-run relationships. Both the inflation rate and the wage inflation rate relate positively with the General Government Balance in percentage of GDP, negatively with the exchange rate index, positively with the foreign inflation index and negatively with the trend. In the short run the variation of the inflation rate relates positively with foreign inflation (or its variation) and the variation in the effective exchange rate, relates negatively with the error correction mechanism, so there is a significant response to the equilibrium error between inflation rate and its determinants. In addition to this adjustment, the inflation rate responds positively and significantly to the lagged variation of the budget deficit, as expected.
\end{abstract}

Keywords: Inflation. Budget deficit. Cointegration.

JEL Classification: C12; C13; C32; E24; E31.

\section{Introduction}

The relationship between the budget deficit and the inflation rate is not a stylized fact. In the economic literature there are at least two approaches, which try theoretically to establish a relation from budget deficit to inflation, but more recently some authors present empirically a relation from inflation to budget deficit.

In the approach of Sargent and Wallace (1981), it is assumed that the fiscal authority takes the measures without taking into account the current or future monetary policies. Thus, the monetary authority has to take restrictive measures in the short-run or in the long-run to defeat inflation. A restrictive monetary policy implies an increase in interest rate and the consequent reduction in product, giving rise to an increase in deficit ceteris paribus the fiscal policy. The fiscal authority will have to finance this increase in deficit, either by money emission, or by indebtedness. In the first case it implies an increase in inflation.

Another approach, suggests that inflation reduces the real stock of public debt, thus people would tolerate an increase in inflation when the deficit is high because they are adverse to an increase of the fiscal burden. However, an increase in inflation, essentially the non-anticipated inflation, represents an inflationary tax.

Professor, Department of Economics, University of Évora, Portugal, and Center for Advanced Studies in Management and Economics of the University of Évora. E-mail: arosa@uevora.pt I am grateful to two anonymous referees and to my colleague Fernanda Peixe. However, any error or omission is solely my responsibility. 
Moreover, budget deficits also represent an additional aggregate demand that will give rise to an increase in inflation.

The economic literature has presented little empirical evidence of inflationary budget deficits. Santos (1992) analyses six countries of the European Union, where only three (including Portugal) seem to present inflationary deficits. Vieira (2000), also analyses six countries of the European Union (excluding Portugal), where it seems to exist more causal evidence from inflation to budget deficit, then in reverse.

The aim of this paper is to analyse if the budget deficit constitutes one of the causes of inflation, inserted in a model that are looking for the main causes of the Portuguese inflation, using annual data for the period 1961-2012. Thus, in section two an explicative model of the inflation will be considered, in section three we will present the chosen data and the reasons for their choice, in section four we will analyse the integration level of the used time series, in section five we will estimate the explicative model of the inflation considered in section two, using the method of Johansen to detect cointegration relations among the non-stationary time series and applying the methodology of Rahbek and Mosconi (1999), which allows us to introduce stationary regressors in the VAR of cointegration through cumulated explanatory variables and simultaneously to use the trace or maximum eigenvalue tests. Finally, in the sixth section we will present the main conclusions.

\section{Model}

The construction of a model is always a simplification of reality, given the multiplicity of variables that influence inflation, among them, an increase in the remuneration of productive factors, an increase in prices of imported products, a variation in the stock of money in circulation, ${ }^{1}$ a variation in the exchange rate, the budget deficit, expectations of inflation and the level and/or the variation in unemployment.

Considering the theory of mark-up, and the possibility of the budget deficit being able to contribute to an increase in inflation, ${ }^{2}$ we can consider the model:

$$
\begin{gathered}
\pi=f\left(\stackrel{(+)}{W}, \stackrel{(+)}{P_{M}}, \stackrel{(+)}{D E F}\right) \\
P_{M} \equiv P_{F}+E
\end{gathered}
$$

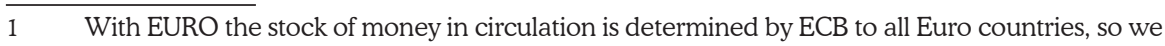
cannot put it in a model to Portugal.

2 See Santos (1992) and Vieira (2000) on the relation between budget deficit and inflation.
} 
Equation (1) contains the cost-push inflation and the budget deficit.

In accordance with the theory of mark-up, the firms set the price of their products above the marginal production cost. However, when the average cost is constant, it has been proved that the marginal cost is equal to the average cost, so that the prices $(\mathrm{P})$ will be given by one mark-up above the average costs $(\mathrm{CM})$ :

$$
P=\theta C M, \quad \theta>1
$$

If mark-up ( $\theta)$ will be constant, the inflation rate $(\pi)$ will be equal to the rate of variation of the average costs. The average costs will vary in accordance with the wage variation $(W)$, and in accordance with the inflation imported in internal currency $\left(P_{M}\right)$. We assumed that the "other internal average costs" are constants.

We include in equation (1) the budget deficit in percentage of GDP (DEF). Here, one admits that an increase in public consumption gives rise to inflation by demand, because the propensity of the government to consume is higher than the propensity of households to consume.

The signals between brackets on variables in equations (1) and (2) correspond to the signals expected for the coefficients of the relation.

The equation (2) is an identity. The foreign inflation $\left(P_{F}\right)$ plus the variation of the effective indirect exchange rate $(E)^{3}$ give the import inflation rate in terms of national currency. The aim of this work is to estimate the equation (1), where we will substitute the variable $P_{M}$ for $P_{F}$ and $E$ in accordance with the equation (2) and we will try to see if budget deficit is inflationary.

\section{Data}

We use annual data whose justification in theoretical terms is given by Campbell and Perron (1991, p. 153) where, either due stationary analysis needs a longterm period, or because "seasonal adjustment procedures often create a bias toward nonrejection of a unit root hypothesis". As stated previously, we formulated the model on the basis of rates of change, so we chose to transform the available annual data into rates of change. ${ }^{4}$ Some authors think that the model would be richer if we used the original data, but we chose rates of change because the variable that we intend to explain (the inflation rate) is generally I(1), so it implies that the consumer price index (CPI) will be I(2), and the model with variables I(2) is not the aim of our study. Thus we selected six annual variables for the period 1961-

\footnotetext{
3 Effective exchange rate is calculated as geometric weighted averages of bilateral exchange rates. Indirect exchange rate means in terms of national currency, that $E>0 \Leftrightarrow$ depreciation. After Euro, we use the variation of effective exchange index to Portugal.

4 With exception of the variable GGB, which is a structure rate.
} 
2012 , which we shall enumerate: $\pi$, inflation rate; $\mathrm{W}$, wage inflation rate; PM, rate of variation in import prices; $\mathrm{E}$, nominal effective indirect exchange rate variation for Portugal; PF, rate of variation in import prices in external currency; GGB, General Government Balance in percentage of $\operatorname{GDPmp}(\mathrm{cp})$ (This variable is symmetrical of the variable DEF in the model 1 ).

The sources of these variables are: variables $\pi, \mathrm{W}$ and PM, source AMECO; variable GGB, sources Bank of Portugal (2014) and Pinheiro et al. (1999); variable E, sources Bank of Portugal (2013) and Mateus (1998); variable PF was calculated by author.

Once variables are selected, we will go on to study its stationarity; therefore the econometric methodology to adopt in the estimation of the model formulated in the equation (1) depends on the integration level of the time series.

\section{Analysis of Stationarity of the Data}

Firstly we carried out tests on the existence of two unit roots, secondly we carried out tests on the existence of a unit root, thirdly we carried out tests on the existence of a unit root in the time series under structural change with endogenous choice of the breakpoint (Tb).

The Dickey and Pantula (1987) test allows us to reject the null hypothesis Ho: I(2) against I(1) in all variables studied to the level of significance of $1 \%$ and $5 \%$ (in case of $\pi$ ).

We applied the $\mathrm{ADF}$ test sequentially, starting with a model with a constant and a trend (CT) and selected $\mathrm{k}$ starting at $\mathrm{k}-\mathrm{max}=6$ and removed the last lag if insignificant at the $5 \%$ level until getting one lag that is significant. We conclude that $\pi, \mathrm{W}$ and GGB are I(1) and PF and E are I(0). Refering to Cruz and Lopes (1999), the fact of $\pi$ to be I(1), are in accordance with those authors.

Using the DG-GLS test of Elliot, Rothemberg and Stock(1996), with a k$-\max =12$ and a SC criterion, we can reach the same conclusion.

Analysing the ADF, DF-GLS and Perron and Vogelsang (1992) tests, we can say that the inflation rate $(\pi)$, wage inflation rate $(\mathrm{W})$ and General Government Balance in percentage of GDPmp (GGB) are I(1) for all the tests, so we must consider these three variables as I(1) in the inflation model estimation, investigating the possibility of existence of relations of cointegration between them. The other variables are all considered I(0). 


\section{Estimation of an Explicative Model of the Inflation}

We use the Johansen method as it allows the detection of more than one cointegrating vector among variables in study.

There are stationary regressors in the VAR model, so we cannot use the critical values of Johansen (1996). Therefore, we follow the methodology of Rahbek and Mosconi (1999), which consists of adding to the VAR the cumulated explanatory I(0) variables as I(1) exogenous variables, and thus the critical values of the trace or eigenvalue tests of, among others authors, Pesaran, Shin and Smith (2000) can be used. ${ }^{5}$ First, as we have exogenous variables, the cointegrated VAR model to use corresponds to the conditional model: ${ }^{6}$

$$
\Delta Y_{t}=\mu_{c}+\delta_{c} t+\sum_{i=1}^{k-1} \Psi_{i} \Delta X_{t-i}+\Pi_{y} X_{t-1}+\omega \Delta Z_{t}+\varepsilon_{c t}
$$

where $X_{t}$ is a $N \times 1$ vector of $I(1)$ variables, which we can partition into $N_{y}$ endogenous I(1) variables (Y) and $N_{z}$ exogenous I(1) variables ( $Z_{t}$ ), such that $N_{y}+N_{z}=$ N. $\Pi_{y}$ is the long-run multiplier matrix of order $\left(N_{y} \times N\right)$ given by $\Pi_{y}=\alpha_{y} \beta$, where $\alpha_{y}$ is a $\left(\mathrm{N}_{\mathrm{y}} \times \mathrm{r}\right)$ matrix and $\beta$ a $(\mathrm{N} \times \mathrm{r})$ matrix of $\mathrm{r}$ cointegranting vectors.

The null hypothesis of the cointegration rank (existence of $r$ cointegrating vectors) is written:

$$
\operatorname{Hr}: R\left[\Pi_{y}\right]=r, \quad r=0, \ldots, N_{y} ;
$$

where " $R$ " is the rank of the matrix.

First, in the estimation of the conditional model (4) we can consider 5 cases (or models) consonant with the restrictions imposed on the deterministic terms, following PSS (2000):

a) Case I (No Intercepts, No Trends):

$$
\mu_{c}=\delta_{c}=0 \Rightarrow \Delta Y_{t}=\sum_{i=1}^{k-1} \Psi_{i} \Delta X_{t-i}+\Pi_{y} X_{t-1}+\omega \Delta Z_{t}+\varepsilon_{c t}
$$

b) Case II (Restricted Intercepts, No Trends):

$$
\left\{\begin{array}{l}
\mu_{c}=-\Pi_{y} \eta \\
\delta_{c}=0
\end{array} \Rightarrow \Delta Y_{t}=\sum_{i=1}^{k-1} \Psi_{i} \Delta X_{t-i}+\Pi_{y}^{*}\left(X_{t-1}^{\prime}, 1\right)^{\prime}+\omega \Delta Z_{t}+\varepsilon_{c t}\right.
$$


c) Case III (Unrestricted Intercepts, No Trends):

$\left\{\begin{array}{l}\mu_{c} \neq 0 \\ \delta_{c}=0\end{array} \Rightarrow \Delta Y_{t}=\mu_{c}+\sum_{i=1}^{k-1} \Psi_{i} \Delta X_{t-i}+\Pi_{y} X_{t-1}+\omega \Delta Z_{t}+\varepsilon_{c t}\right.$

d) Case IV (Unrestricted Intercepts, Restricted Trends):

$\left\{\begin{array}{l}\mu_{c} \neq 0 \\ \delta_{c}=-\Pi_{y} \gamma\end{array} \Rightarrow \Delta Y_{t}=\mu_{c}+\sum_{i=1}^{k-1} \Psi_{i} \Delta X_{t-i}+\Pi_{y}^{* *}\left(X_{t-1}^{\prime}, t\right)^{\prime}+\omega \Delta Z_{t}+\varepsilon_{c t}\right.$

where $\Pi_{y}^{* *}=\Pi_{y}\left(I_{N},-\gamma\right)$.

e) Case V (Unrestricted Intercepts, Unrestricted Trends):

$\left\{\begin{array}{l}\mu_{c} \neq 0 \\ \delta_{c} \neq 0\end{array} \Rightarrow\right.$ We estimate the model in equation (4).

Second, as we follow the methodology of Rahbeck and Mosconi (1999), so $\mathrm{I}(0)$ variables are included in $\Delta Z_{t}$ in equation (4) or in one of the 5 cases (models) consonant with the choice that is made. The cumulative sum of these $\mathrm{I}(0)$ variables are $\mathrm{I}(1)$ variables, corresponding to $\mathrm{Z}_{\mathrm{t}}$ in the previous equation, enclosed therefore in $\mathrm{X}_{\mathrm{t}}$.

After this brief introduction, we will try to estimate the corresponding model to the equation (1).

\subsection{Estimation of the Long-Run Model}

In the Model $\pi=\mathrm{f}(\mathrm{W}, \mathrm{PF}, \mathrm{E}, \mathrm{GGB})$, corresponding to equation (1), we start by having three endogenous $\mathrm{I}(1)$ variables $(\pi, \mathrm{W}, \mathrm{GGB})$ and two exogenous $\mathrm{I}(0)$ variables $(\mathrm{PF}, \mathrm{E})$.

As far as the order of the VAR is concerned, we selected VAR(3), using either multivaried statistics, or univaried statistics, so that the estimated residuals have no serial correlation (LM test), no autoregressive conditional heteroscedasticity (ARCH test), and they do not deviate too much from normality (BJ test), as Johansen (1996, p. 20) recommends.

We cannot reject the weak exogeneity of the General Government Balance in percentage of GDPmp (GGB) in the models II and III ${ }^{7}$ with one cointegrating vector and in model IV with two cointegrating vectors, on the significance level of $5 \%$ (Table 1).

$7 \quad$ PSS(2000) models. 
Table 1 - Weak exogeneity test ${ }^{8}$ of unemployment rate (U)

\begin{tabular}{c|c|c|c}
\hline Model & Model II & Model III & Model IV \\
\hline LR test & $\chi^{2}(1)=2.77[0.10]$ & $\chi^{2}(1)=2.05[0.15]$ & $\chi^{2}(2)=4.41[0.11\}$ \\
\hline
\end{tabular}

Source: Calculations were performed by the author.

Note: The null hypothesis is Ho: $\alpha_{U}=0$.

We estimated the model with two endogenous I(1) variables ( $\pi$ and $W$ ), one $\mathrm{I}(1)$ exogenous variable (GGB), and two I(0) variables (E and PF), in accordance with Rahbek and Mosconi(1999) methodology, introducing the cumulated explanatory $\mathrm{I}(0)$ variables into the cointegration relation as I(1) exogenous variables:

$\pi \mathrm{W}$; GGB csumE csumPF $\mathcal{E} \Delta \mathrm{GGB} E \mathrm{PF}$

As we use the variable GGB and not the variable DEF as in equation (1), the signal expected in the relation between $\pi$ and GGB will be negative, that is, when the budget deficit increases, the budget balance diminishes and one expects that the inflation rate also increases.

We confirm the k order of the VAR with endogenous GGB, as a VAR(3) and the methodology of PSS(2000) leads us to choose model IV.

Given VAR(3) and Model IV, we cannot reject the existence of two cointegranting vectors, either by the trace test, or by the maximum eigenvalue test, as we can see in Table 2.

Table 2 - Cointegration tests

\begin{tabular}{c|c|c|c|c|c|c}
\hline \multirow{2}{*}{$\begin{array}{c}\text { Eigenvalue } \\
\lambda\end{array}$} & \multicolumn{3}{|c|}{ Trace test } & \multicolumn{3}{c}{ Maximal eigenvalue test } \\
\cline { 2 - 7 } & Ho & Ha & Trace & Ho & Ha & $\lambda$ max \\
\hline 0.57711 & $\mathrm{r}=0$ & $\mathrm{r} \geq 1$ & $59.2104^{*}$ & $\mathrm{r}=0$ & $\mathrm{r}=1$ & $38.1286^{*}$ \\
\hline 0.24687 & $\mathrm{r} \leq 1$ & $\mathrm{r}=2$ & $21.0818^{*}$ & $\mathrm{r} \leq 1$ & $\mathrm{r}=2$ & $21.0818^{*}$ \\
\hline
\end{tabular}

Source: Calculations were performed by the author.

$*$ significant at $5 \%$.

The AIC, SBC and HQC criterions also selects the model with $r=2$. The vectors 1 and 2 normalized in relation to $\pi$ and $\mathrm{W}$ respectively (and identified) without restrictions with $X^{\prime} t=\left[\pi \mathrm{W}\right.$ GGB csumE csumPF Trend] are given by: ${ }^{9}$

$$
\beta_{1}^{\prime}=\left[\begin{array}{cccccc}
1 & 0 & -0.91856 & 0.10868 & -0.37540 & 0.52708 \\
& & (0.30766) & (0.029725) & (0.064032) & (0,077728)
\end{array}\right]
$$

8 Produced on CATS in RATS by the restriction $\mathrm{B}^{\prime *}$ alpha $=0$ with $\mathrm{B}^{\prime}=\left[\begin{array}{lll}0 & 0 & 1\end{array}\right]$ selecting $\mathrm{r}=1$ in models II e III and $r=2$ in model IV, in the model $\pi$ W GGB; csumE csumPF $\mathcal{E}$ E PF, lag 3.

9 Between round brackets in the cointegrating vectors we have the standard errors. 


$$
\beta_{2}{ }^{\prime}=\left[\begin{array}{ccccc}
1 & -1.6491 & 0.12100 & 0.53329 & 0.96453 \\
& (0.22818) & (0.022046) & (0.047491) & (0.057649)
\end{array}\right]
$$

where we cannot excluded any variable from the cointegrating vectors, so we have the two ecms:

ecm $1=\pi-0.91856 *$ GGB $+0.10868 * \operatorname{csumE}-0.37540 *$ csumPF $+0.52708^{*}$ Trend ecm $2=\mathrm{W}-1.6491{ }^{*} \mathrm{GGB}+0.12100^{*} \mathrm{csumE}-0.53329^{*} \mathrm{csumPF}+0.96453^{*}$ Trend

which represents two long-run relationships: one of them relates the inflation rate with GGB, CSUME, CSUMPF and Trend, the other relates the wage inflation rate with the same variables. Either the inflation rate $(\pi)$, or the wage inflation rate $(\mathrm{W})$ relates positively with the General Government Balance in percentage of GDPmp (GGB), negatively with the exchange rate index (csumE), positively with the foreign inflation index (csumPF) and negatively with the trend (Trend).

\subsection{Estimation of the Short-Run Model}

The estimation of the multivaried model only with variables introduced initially in $\operatorname{VAR}(3)$ allows us to get the results in Table 3.

Analysing these equations, we verify that the variation of the inflation relates positively and significantly at $1 \%$ level to the foreign inflation and the variation of the exchange rate as expected, and relates negatively to $\mathrm{PF}_{\mathrm{t}-1}$ and positively to $\Delta \mathrm{P}_{\mathrm{t}-2}$ at $5 \%$. The variation of inflation relates negatively and significantly at $10 \%$ level to $\Delta \mathrm{GGB}_{\mathrm{t}-1}$, which means that it relates positively to the lagged variation of the budget deficit.

The long-run relationship represented by ECM1 (which corresponds to the long-run relationship between inflation rate and others variables) is significant at $1 \%$, but that represented by ECM2 is not significant.

The variation of wage inflation relates significantly at $1 \%$ level, positively to the foreign inflation and negatively to the variation of exchange rate. The variation of wage inflation relates positively and significantly at $5 \%$ level to lagged variation of wage inflation rate.

The variation of wage inflation relates negatively and significantly at $1 \%$ level to $\Delta \mathrm{GGB}_{\mathrm{t}-1}$ and $\Delta \mathrm{GGB}_{\mathrm{t}-2 \text {, }}$ which means that it relates positively to the lagged one and two periods variation of the budget deficit. How can we explain this? We can say that, the high budget deficit in the last periods could increase the inflationary expectations, which would imply some pressing in wage increase. 
The long-run relationship represented by ECM1 is significant at 5\%, and that represented by ECM2 (which corresponds to the long-run relationship between wage inflation rate and others variables) is significant at $1 \%$.

Table 3 - Estimation of the multivaried model

\begin{tabular}{|c|c|c|}
\hline Equation & $\Delta \pi$ & $\Delta \mathbf{W}$ \\
\hline $\begin{array}{c}\mathbf{N}^{\circ} \text { observations/ } \\
\text { Regressors }\end{array}$ & $\begin{array}{c}T=49 \\
{[64-12]}\end{array}$ & $\begin{array}{c}T=49 \\
{[64-12]}\end{array}$ \\
\hline INPT & $5.5940[.022]$ & $13.5686[.000]$ \\
\hline$\Delta \pi(-1)$ & $.10310[.600]$ & $.046572[.832]$ \\
\hline$\Delta \mathrm{W}(-1)$ & $-.097085[.518]$ & $.34861[.044]$ \\
\hline$\Delta$ GGB $(-1)$ & $-.39797[.086]$ & $-1.0378[.000]$ \\
\hline $\mathrm{E}(-1)$ & $-.18327[.187]$ & $-.13335[.386]$ \\
\hline $\mathrm{PF}(-1)$ & $-.21153[.014]$ & $-.28820[.003]$ \\
\hline$\Delta \pi(-2)$ & $.27591[.037]$ & $-.23632[.104]$ \\
\hline$\Delta \mathrm{W}(-2)$ & $.061122[.560]$ & $.092440[.431]$ \\
\hline$\Delta$ GGB $(-2)$ & $-.20389[.355]$ & $-.75414[.004]$ \\
\hline $\mathrm{E}(-2)$ & $.059477[.624]$ & $-.022337[.869]$ \\
\hline $\mathrm{PF}(-2)$ & $-.13171[.174]$ & $-.14806[.171]$ \\
\hline $\operatorname{ECM} 1(-1)$ & $-.79206[.001]$ & $.52647[.036]$ \\
\hline $\operatorname{ECM} 2(-1)$ & $-.079497[.701]$ & $-1.3835[.000]$ \\
\hline$\Delta$ GGB & $.25549[.155]$ & $.37406[.065]$ \\
\hline E & $.29422[.005]$ & $-.40917[.001]$ \\
\hline $\mathrm{PF}$ & $.35952[.000]$ & $.28358[.000]$ \\
\hline$\overline{\mathbf{R}}^{2}$ & .72910 & .75935 \\
\hline SEE & 1.9705 & 2.2004 \\
\hline DW & 1.9940 & 2.1044 \\
\hline $\operatorname{LM}(1,32)$ & $.066467[.798]$ & $.85459[.362]$ \\
\hline $\operatorname{RESET}(1,32)$ & $.31839[.577]$ & $.12918[.722]$ \\
\hline $\mathrm{BJ}(2)$ & $.83822[.658]$ & $1.5507[.461]$ \\
\hline $\operatorname{HET}(1,47)$ & $.011721[.914]$ & 1.9267[.172] \\
\hline $\mathrm{ARCH}(3,30)$ & $.41858[.741]$ & $.15488[.926]$ \\
\hline
\end{tabular}

Source: Calculations were performed by the author. 
The diagnostic tests indicate that the residuals are not autocorrelated, are homoskedastic, normal and we cannot reject correct specification of the model. The autoregressive conditional heteroskedasticity is also absent until the third order.

In both equations, all the residuals are inside the line bands of double standard deviation and CUSUM and CUSUMSQ tests do not cross any of the significant bars at $5 \%$ level.

We tried to remove from the equation of $\Delta \pi$ the variables that were not significant at the $10 \%$ level, using the Wald test on the joint nullity of its coefficients, to reestimate parsimonious equations. We cannot reject the exclusion of these variables from the model with the $\chi^{2}(9)=12.6853$ [.177] and we cannot reject the exclusion of these variables plus the variable $\Delta \pi_{\mathrm{t}-2}$ from the model with the $\chi^{2}(10)=$ 12.7654[.237]. So we have the parsimonious equations of $\Delta \pi$ (Table 4).

Table 4 - Parsimonious Equations of $\Delta \pi$

\begin{tabular}{|c|c|c|c|c|c|c|}
\hline \multirow{2}{*}{$\begin{array}{l}\text { Equation/ } \\
\text { Regressors }\end{array}$} & DP1 & DP2 & DP3 & DP4 & DP5 & DP6 \\
\hline & $\begin{array}{c}T=50 \\
{[63-12]}\end{array}$ & $\begin{array}{l}T_{1}=37, T_{2}=13 \\
{[63-99]}\end{array}$ & $\begin{array}{c}\mathrm{T}=39 \\
{[74-12]}\end{array}$ & $\begin{array}{c}\mathrm{T}=26 \\
{[74-99]}\end{array}$ & $\begin{array}{c}\mathrm{T}=50 \\
{[63-12]}\end{array}$ & $\begin{array}{c}\mathrm{T}=39 \\
{[\mathbf{7 4 - 1 2}]}\end{array}$ \\
\hline Inpt & $5.1517[.000]$ & $5.6365[.000]$ & $5.1704[.000]$ & $5.4682[.000]$ & $5.2337[.000]$ & $5.1806[.000]$ \\
\hline$\Delta \mathrm{GGB}(-1)$ & $-.30116[.041]$ & $-.47225[.032]$ & $-.32157[.029]$ & $-.52210[.019]$ & $-.40659[008]$ & $-.44157[.003]$ \\
\hline $\mathrm{PF}(-1)$ & $-.22613[.000]$ & $-.26183[.000]$ & $-.23294[.000]$ & $-.27177[.000]$ & $-.24064[.000]$ & $-.24831[.000]$ \\
\hline $\operatorname{ECM1}(-1)$ & $-.74065[.000]$ & $-.81581[.000]$ & $-.76537[.000]$ & $-.84470[.000]$ & $-.76945[.000]$ & $-.79593[.000]$ \\
\hline $\mathrm{E}$ & $.18616[.000]$ & $.21056[.000]$ & $.20254[.000]$ & $.24034[.000]$ & $.19947[.000]$ & $.22099[.000]$ \\
\hline PF & $.35869[.000]$ & $37483[.000]$ & $.36469[.000]$ & $38462.007]$ & $.36258[.000]$ & $.36889[.000]$ \\
\hline DumTroika & - & - & - & - & $3.2159[.042]$ & $3.6073[.019]$ \\
\hline$\overline{\mathbf{R}}^{2}$ & .69942 & .75422 & .75717 & .83234 & .72098 & .78965 \\
\hline SEE & 2.0550 & 2.1236 & 2.0053 & 2.0054 & 1.9799 & 1.8663 \\
\hline DW & 1.8084 & 1.7405 & 1.8647 & 1.9346 & 1.7912 & 1.8998 \\
\hline $\mathrm{LM}(1, \mathrm{~T}-\mathrm{k}-1)$ & $.30719[.582]$ & $.42699[.518]$ & $.059819[.808]$ & $.5395 \mathrm{E}-3[.982]$ & $.41251[.524]$ & $.014197[.906]$ \\
\hline $\operatorname{RESET}_{(1, \mathrm{~T}-\mathrm{k}-1)}$ & $.026221[.872]$ & $.038489[.846]$ & $.0026307[.959]$ & $.017025[.898]$ & $.046801[.830]$ & $.0018821[.966]$ \\
\hline $\mathrm{BJ}(2)$ & $.048266[.976]$ & $.074524[.963]$ & $.60490[.739]$ & $.88645[.642]$ & $.025627[.987]$ & $.94187[.624]$ \\
\hline $\operatorname{HET}(1, \mathrm{~T}-2)$ & $.022131[.882]$ & $.034229[.854]$ & $.7879 \mathrm{E}-6[1.00]$ & $.16837[.685]$ & $.021602[.884]$ & $.48171[.492]$ \\
\hline $\mathrm{ARCH}(3, \mathrm{~T}-\mathrm{k}-3)$ & $.25829[.855]$ & $.13577[.938]$ & $.42072[.739]$ & $.60148[.623]$ & $.16074[.922]$ & .62576[.604] \\
\hline $\operatorname{Chow}\left(\mathrm{T}_{2}, \mathrm{~T}_{1}-\mathrm{k}\right)$ & - & $.78482[.670]$ & - & $.99968[.486]$ & - & \\
\hline $\operatorname{Cov}\left(k, T_{1}+T_{2}-2 k\right)$ & - & $1.7143[.144]$ & - & $2.3745[.057]$ & - & \\
\hline
\end{tabular}

Source: Calculations were performed by the author.

Notes: Dependent Variable: $\Delta \pi$; Estimation Method: OLS; ECM1= $\pi-.91856 \mathrm{GGB}+.10868 \mathrm{csumE}-.37540 \mathrm{csumPF}+.52708$ Trend estimated on model: $\pi \mathrm{W}$; GGB csumE, csumPF $\& \Delta$ GGB E PF.

Between square brackets: $\mathrm{p}$-value or sample period (on the top). On the estimated coefficients, the null hypothesis is Ho: $\beta=0$, and the Student $t$ test is used. $\mathrm{T}=$ number of observations used in regression; $k=$ number of estimated coefficients; $T_{1}=$ sub-sample used in estimation; $\mathrm{T}_{2}=$ Period post-sample (forecasting test) or second sub-sample (stability test, only possible when $\mathrm{T}_{1}>\mathrm{k}$ and $\mathrm{T}_{2}>\mathrm{k}$ ). LM - statistic of Lagrange Multiplier test for serially correlated residuals; RESET - statistic of Ramsey's RESET test of functional form misspecification; BJ - statistic of Jarque-Bera's test of normality of regression residuals; HET - statistic of Heteroskedasticity test; ARCH - statistic of Autoregressive Conditional Heteroskedasticity test [Engle's test]; Chow-statistic of Predictive failure test ( $2^{\text {nd }}$ test of Chow);Cov - statistic of Chow's test of stability of regression coefficients ( $1^{\text {st }}$ test of Chow). 
At the parsimonious equation DP1 (Table 4), foreign inflation (PF), lagged foreign inflation $\left(\mathrm{PF}_{\mathrm{t}-1}\right)$, variation of exchange rate $(\mathrm{E})$ and $\mathrm{ECM} 1_{\mathrm{t}-1}$ are significant at $1 \%$, and $\Delta \mathrm{GGB}_{\mathrm{t}-1}$ is significant at $5 \%$. Reestimating the previous equation for 196399 (equation DP2), we cannot reject, either the predictive capacity after-1999 or the structural stability before and after 1999, using the Chow (1960) tests.

The DP equation estimated for the period post-25 ${ }^{\text {th }}$ April (1974-2012) [DP3 Equation], have, more or less, the same coefficients estimated for the period 19632012. In this period, we cannot also reject either the predictive capacity after-1999, or structural stability before and after 1999 (DP4 equation).

The introduction of dummies variables ${ }^{10}$ (equations DP5 and DP6) allows us to verify that there is one of them significant (DumTroika), which contribute to increase inflation, but diminishes the coefficient of $\Delta \mathrm{GGB}_{\mathrm{t}-1}$.

In all the estimated equations, we can verify the coefficient stability as the Chow (1960) testes suggest. The coefficient of $\Delta \mathrm{GGB}_{\mathrm{t}-1}$ varies between -0.30 and -0.52 through the six equations, being higher, in absolute value, without the period post-EMU (1999-2012), so in the whole period is about $-0,3$. With dumTroika diminishes to $-0,4$. The coefficient of $E C M 1_{t-1}$ varies between -0.74 and $-0,84$ through the six equations, being higher, in absolute value, without the period postEMU, so in the whole period is about $-0,75$. The coefficients of the other variables is more stable: the coefficient of $\mathrm{PF}_{\mathrm{t}-1}$ varies between $-0,22$ and $-0,27$, the coefficient of $\mathrm{E}$ varies between 0,18 and 0,24, and the coefficient of $\mathrm{PF}$ varies between 0,35 and 0,38 through the six equations, being higher, in absolute value, without the period post-EMU.

In all equations of the parsimonious model, CUSUM and CUSUMSQ tests do not cross any of the significant bars at $5 \%$ level. All the residuals are inside the line bands of double-standard deviation, except for the equations DP1 and DP5 where we verify that the plot of residuals crosses two standard error bands in 1971.

\section{Final Considerations}

In the long run there are two long-run relationships. Both the inflation rate and the wage inflation rate relates positively with the General Government Balance in percentage of GDP, negatively with the exchange rate index, positively with the foreign inflation index and negatively with the trend.

In the short run the variation of the inflation rate relates positively with foreign inflation (or its variation) and the variation in the effective exchange rate, relates negatively with the error correction mechanism, so there is a significant

$10 \quad$ Dum74 (value 1 in 1974 - first oil shock and April Revolution), DumEMU (value 1 after 1999 Euro) and DumTroika (value 1 in 2011-2012 - Financial Rescue Plan to Portugal). 
response to the equilibrium error between inflation rate and its determinants. In addition to this adjustment, the inflation rate responds positively and significantly to the lagged variation of the budget deficit, as expected.

The main causes of the variation in inflation in the period 1961-2012 seem to be foreign inflation (or its variation) and the variation in the effective exchange rate, but the lagged variation of budget deficit seems to causes variation of inflation in the studied period.

\section{References}

BANK OF PORTUGAL. Annual Report: The Portuguese Economy in 2012. Lisbon: Bank of Portugal, 2013. Available in: <www.bportugal.pt>. Access in: February $22^{\text {th }}, 2014$.

Statistical Bulletin. Lisbon: Bank of Portugal, Jan. 2014.

CAMPBELL, J. Y.; PERRON, P. Pitfalls and opportunities: what macroeconomics should know about unit roots. NBER Macroeconomics Annual, v. 6, n. 100, p. 141-201, 1991.

CHOW, G. C. Tests of equality between sets coefficients in two linear regressions. Econometrica, v. 28, n. 3, p. 591-605, 1960.

CRUZ, P. M.; LOPES, A. S. Raízes unitárias e quebras de estrutura: evidência empírica para a economia portuguesa. Estudos de Economia, v. 19, n. 2, p. 233-263, 1999.

DICKEY, D. A.; PANTULA, S. G. Determining the order differencing in autoregressive processes. Journal of Business and Economic Statistics, v. 5, n. 4, p. 455-461, 1987.

ELLIOT, G.; ROTHEMBERG, T. J.; STOCK, J. H. Efficient tests for an autoregressive unit root. Econometrica, v. 64, n. 4, p. 813-836, 1996.

JOHANSEN, S. Likelihood-based inference in cointegration vector autoregressive models. Oxford: Oxford University Press, 1996.

MATEUS, A. Economia portuguesa: desde 1910. Lisbon: Editorial Verbo, 1998.

PERRON, P.; VOGELSANG, T. J. Nonstationarity and level shifts with an application to purchasing power parity. Journal fo Business and Economic Statistics, v. 10, n. 3, p. 301-320, 1992.

PESARAN, M. H.; SHIN, Y.; SMITH, R. J. Structural analysis of vector error correction models with exogenous I(1) variables. Journal of Econometrics, v. 97, n. 2, p. 293-343, 2000.

PINHEIRO, M. et al. Historical series for the portuguese economy: post II World War. Bank of Portugal, 1999. Available in: <www.bportugal.pt>. Access in: January $28^{\text {th }}, 2006$.

RAHBEK, A.; MOSCONI, R. Cointegration rank inference with stationary regressors in VAR models. Econometrics Journal, v. 2, n. 1, p. 76-91, 1999.

SANTOS, J. Budget deficits and inflation: Portugal and the other ec high debt countries. Estudos de Economia, v. 12, n. 3, p. 245-253, 1992. 
SARGENT, T.; WALLACE, N. Some unpleasant monetarist arithmetic. Federal reserve Bank of Minneapolis Quarterly Review, Fall:1-17, 1981. Available in: <http://minneapolisfed.org/ research/qr>. Access in: August $8^{\text {th }}, 2005$.

VIEIRA, C. Are fiscal deficits inflacionary? Evidence for the EU. Loughborough: Loughborough University, 2000. (Working Paper, n. 00/07). Available in: <www.lboro.ac.uk/ departments/ec/Reasearchpapers/2000/00-7/erp00-7.PDF >. Access in: December $5^{\text {th }}, 2006$.

Recebido em: 11/08/14. Aceito em: 03/08/16. 